\title{
Short-term culture of monocytes as an in vitro evaluation system of of bio- nanomaterials for medical use
}

Menzianova Natalia Gennadievna (1), Shishatskaya Ekaterina Igorevna (1), Shabanov Alexander Vasilievich (2), Dragana Nikitovic (3)

1) Siberian Federal University, Svobodnuy av. 79, Krasnoyarsk,660041, Russia

2) Institute of Physics, Russian Academy of Science, Siberian Division, Akademgorodok, 50, build. 38, Krasnoyarsk, 660036, Russia

3) Laboratory of Anatomy, Histology, Embryology, School of Medicine, University of Crete, Heraklion 71003, Greece

\section{SUMMARY}

We studied the possibility of using a short-term culture of monocytes, isolated from peripheral donor blood, to assess the biological activity of different types of bio-nanomaterials (BNM): biodegradable polimeric particles, fiber and film substrates of micro- and nano-dimentions, fullerenes (F) and nanodiamonds (ND), which are either currently in use and/or potentially applicable in medicine. Additionally, affect of preforming protein corona on ND and F, was investigated. The cellular reduction of (4,5-dimethylthiazol-2-yl)-2,5-diphenyltetrazolium bromide (MTT) is a well-established tool for assessing the metabolic activity of cells. Therefore, in the present study the biological activity of nanomaterials was evaluated by assessing cellular reduction of MTT, so as by determining changes in cell morphology in the direct contact with samples. BNM have been shown to affect; in a size, chemical composition and morphological characteristicsdependent manner, cellular reduction of MTT, so as cell morphology: ND and F exhibited specific effects in a dose-dependent manner, which was sensitive to the formation of protein corona on the surface of the nanoparticles. Our results suggest that short-term culture of monocytes is a sensitive model system for assessing the biological effects of nanomaterials in vitro.

KEYWORDS: biocompatible biopolymers, polyhydroxyalkanoates, nanomaterials, nanodiamonds, fullerenes, bio-nanomaterials, monocytes. 
Nanoparticles (NPs) are characterized by their small size (1-100 nm in diameter), unique ratio of surface area to volume, multiple variations in particle shape, as well as discrete mechanical, optical, magnetic and electronic properties (Farokhzad O., Langer R. , 2006). The widespread use of nanomaterials in regenerative technologies, diagnostics and targeted therapy actually is complicated by their side cytotoxic effects (Khalili et al., 2015). An important fact of nanomaterial toxicity and due to their structural properties is the induction of mechano-chemical signal translation.

Thus, the interactions of nanomaterials with biomembranes, through the application of different physical forces, may lead to the activation of an unique receptor-independent signaling mechanisms which translate membrane deformations into chemical signal transduction cascades, and change cell morphology (Galic et al, 2014.; Echarri et al., 2015). Therefore, these physical forces, arising in the plasma membrane during the interaction and the internalization processes of the nanoparticles, NPs, trigger nanoscale membrane deformations, which are then translated into biochemical signals regulating various biological functions (Bharde et al., 2013; Lee et al., 2014; Curtis et. al., 2014; Henstock, et al., 2014, 2015; Kilinc et al., 2016).

Indeed, ambiguous effects of NPs on cell differentiation and proliferation as well as on lipid metabolism can be linked with non-receptor signaling cascades also (Klotzsch E. et al., 2014)

Finally, the biological effects of NPs, including their cytotoxicity, can be largely modified with the formation of protein "corona", formed through adsorption of various proteins on the surface of the NPs. Features of protein corona, PC, determine the manner of internalization, the cascades of intracellular signaling and effector targets, including lipid metabolism system, redox homeostasis, proinflammatory and anti-inflammatory responses (Fleischer et al., 2014; Mortimer et al., 2014; Hata et al., 2014; Shannahan et al., 2015; Matczuk et al., 2015; Di Silvio et al., 2015; Zanganeh et al., 2016; Polyak et al., 2016).

Cytotoxicity, non-receptor signaling as well as the formation of the PC underlie the ambiguity of NPs effects and reduce their effectiveness as therapeutic agents and bioimplants. These highlight the need for the design of effective evaluation systems for assessing NPs and BNMs biological activity in vitro, which will allow for selection of the most "safe" version of nanosized particles and materials and facilitate their use for functional engineering in medicine.

Short-term culture of monocytes, isolated from peripheral blood of healthy donors or patients, as a system for BNMs-screening is one of the biologically "reasonable" options. This option is further argued by the fact that the clearance of NPs and biodegradation of nanocomposite implants in vivo depend largely on the functional activity of the monocyte-macrophage system (Damanik et al., 2014; Trindade et al., 2014; Zandstra et al., 2014; Anderson, 2015; Majd et al., 
2015). Moreover, a simple well-reproducible procedure for the separation of monocytes from peripheral blood enables the establishment of a high through output evaluation system, capable of assessing the individual features of the BNMs biological effects. This is all the more important as the functional monocyte-macrophage activity in vitro (for example, the ratio of phenotypes M1 and M2) varies considerably among different donors (Damanik et al., 2014; Grotenhuis et al., 2014).

Typically in in vitro screening systems the effects of the tested factors on specific integral parameters, e.g. cell viability and morphology are evaluated. Analysis of integral parameters is sufficient to address the specific interim goals and select the most promising groups of BNMs for further functionalization and application in medicine.

Therefore, we investigated the feasibility of using of monocytes short-term culture for in vitro evaluation of different BNMs effects utilizing changes in metabolic activity and cell morphology as end points.

\section{MATERIALS AND METHODS.}

\section{Materials}

Biopolymer BNMs - particles, fibers and films substrates - were prepared from the biopolymers from group of polyhydroxyalcanoates (PHAs), synthesized in culture Ralstonia eutropha B5786 in specific cultivation conditions. The polymer samples were provided by the head of Laboratory of Chemoautotrophic biosynthesis of Institute of biophysics, RASSD, professor, Dr. Tatiana Volova. As a reference polymer biomaterials were used representatives from the same chemical group, which are widely use in medicine as implantable materials, polylactic acid, PLA, and polylactic-co-polyglycolic acid, PLA/PGA, of Sigma, USA.

Stable aqueous suspensions of nanodiamonds (ND) and fullerenes (F) were provided by Alexey Puzir, Laboratory of Biotechnology and Bioluminescence of the same Institute of biophysics. The average diameter of ND was $54,07 \pm 0,35 \mathrm{~nm}$, the polydispersity index $\mathrm{PdI}=$ $0,225 \pm 0,005$. The average diameter of $\mathrm{F}$ was $94,64 \pm 3,12 \mathrm{~nm}$, polydispersity index $\mathrm{PdI}=0,482 \pm 0,031$. Dimensional characteristics of $\mathrm{ND}$ and $\mathrm{F}$ have allowed us to imagine nonreceptor internalization for these particles and the expected specific morphological changes of cell membranes.

Preparation of biopolymer particles, fibers and films substrates. 
The biopolymer particles and fibers substrates were prepared from poly-3-hydroxybutyrate (P3HB) and poly-[3-hydroxybutyrate-co-4-hydroxybutyrate] with $10 \mathrm{~mol} . \%$ of 4-hydroxybutyrate inclusion (P3HB/4HB10). Films substrates were prepared from P3HB/4HB10.

\section{Particles}

Biopolymer particles were prepared by evaporation of the solvent from the emulsion of viscous solutions of polymers. Shortly, the polymer solution in dichloromethane with $1 \%$ surfactant by adding $1 \%$ of polyvinyl alcohol was dispersed with a mechanical stirrer, fitted with a three-blade propeller and/or by «Sonicator» ultrasonic generator 3000 (Misonix Incorporated, USA). After evaporation of the solvent, microspheres were collected by centrifugation at $10000 \mathrm{rpm} / \mathrm{min}$, washed, dried under vacuum and lyophilized with Martin Christ ALPHA 2-4 LDplus (Martin Christ Gefriertrocknungsanlagen $\mathrm{GmbH}$, Germany). The dimensions of particles obtained ranged from 20 $\mathrm{nm}$ to $500 \mathrm{~nm} \pm 7 \mathrm{~nm}$. To isolate the fraction up to $200 \mathrm{~nm}$, particles were suspended in DMEM, supplemented with $10 \%$ fetal calf serum and antibiotics (streptomycin $100 \mathrm{ug} / \mathrm{ml}$, penicillin 100 U/ml, Gibco, Invitrogen, USA), and filtered through a membrane filter Sartorius, Germany. This fraction of particles we considered as nano-sized. Membrane filters were rinsed with DMEM medium to obtain coarse fraction (particles greater than $200 \mathrm{~nm}$, micro-sized).

\section{Fibers substrates}

Fibers are obtained by the electrostatic spinning with Nanon 01A, MECC, Japan. 5\% biopolymers chloroformic solutions were fed at a rate of $5 \mathrm{~mL} / \mathrm{h}$ in an electric field of 6-30 kV. As a biopolymers we used P3HB, its mixture with PLA as 50/50, and with PLA/PGA $\mathrm{P} 3 \mathrm{HB}+\mathrm{PL}+\mathrm{PG}$, as 50/25/25; for PHB oriented and non-oriented substrates were assessed. As the accepting target fat-free glass slides were used in all samples.

\section{Films substrates}

The polymeric films were prepared by pouring of the P3HB/4HB10-chloroformic solutions on glass fat-free surface followed by complete evaporation of solvent in the laminar box at stable temperature and air flow.

\section{Preforming of the protein crow on ND and $F$ nanoparticles}

In short, $100 \%$ fetal serum was added to aliquots of sterile aqueous solutions of ND or F (1:1 by volume) and incubated for $5 \mathrm{~min}$. The modified ND and F were diluted with DMEM, and $10 \%$ fetal serum to the required concentrations. 
Monocytes were isolated from peripheral blood of healthy donors in the density gradient of urografin/Ficoll by the method Recalde (1984). Isolated monocytes were resuspended in DMEM, $10 \%$ fetal serum, in continuation referred to as culture media (CM). The cells were allowed to attach during two hours and in continuation the non-adherent cells were removed by aspiration.

In experiments with $\mathrm{P} 3 \mathrm{HB}$ - and and P3HB/4HB10 - fibers substrates, the sterile substrates were placed on the bottom of 96-well culture plates, to which $10^{5}$ cells in $160 \mu \mathrm{L} \mathrm{CM}$ per well were added. In experiments with P3HB- and P3HB/4HB -particles 105 cells in $80 \mu \mathrm{L} \mathrm{CM}$ and 80 $\mu \mathrm{L}$ of particles solutions in $\mathrm{CM}$ per each well were added; the final particle concentrations were 0,5 $\mathrm{mg} / \mathrm{mL}$. As a control, plates containing only $10^{5}$ cells in $160 \mu \mathrm{L} \mathrm{CM}$ per well were utilized.

In experiments with ND and F in control and treatment samples at the bottom of the 96wells sterile PHB-film substrates were placed. For control samples $10^{4}$ cells in $160 \mu \mathrm{L} \mathrm{CM}$ per well were added. In treatment samples 105 cells in $80 \mu \mathrm{L}$ of $\mathrm{CM}$ and $80 \mu \mathrm{L}$ of solutions of NA or F in CM per well were added. The final F and ND - concentrations were 2,5 $\mu \mathrm{g} / \mathrm{mL}, 25 \mu \mathrm{g} / \mathrm{mL}$ and 50 $\mu \mathrm{g} / \mathrm{mL}$.

Control and treated cells were cultured during 36 hours in a CO 2-incubator Sanyo, Japan. MTT-test

The potential cytotoxicity of BNMs was evaluated by measuring the cellular reduction of MTT. Metabolic activity of cells was tested in all groups after 36 hours. All tests were performed at least 3 times in order to ensure the reproducibility of results. Respectively, upon the completion of treatment, the test and control groups were exposed to sterile solution of $5 \mathrm{mg} / \mathrm{ml}$ MTT powder (Sigma Chemical Co, St Louis, MO, USA) in PBS, according to the manufacturer's instructions. All samples were then incubated at $37^{\circ} \mathrm{C}$ in humid atmosphere for another four hours. Upon centrifugation of the plates the supernatant was discarded, cells were ruptured by adding of isopropanol and $0.04 \%$ hydrochloric acid $(100 \mu l)$. The results were read by iMark ${ }^{\mathrm{TM}}$ Microplate Absorbance Reader (Bio-Rad, USA) at a wavelength of $570 \mathrm{~nm}$ considering 630nm wavelength as the reference. The optical density (for $\lambda=570 \mathrm{~nm}$ ) of control samples were taken as $100 \%$. Meanings of MTT-reduction in treated groups were expressed as a percentage of control.

\section{Scanning electron microscopy assay}

After completion of the incubation, the culture medium was removed and cells were fixated in wells of plates with $2.5 \%$ glutaraldehyde (in phosphate buffer, $\mathrm{pH}=$ 7.4), $1 \mathrm{~h}$ at $4^{\circ} \mathrm{C}$ in refrigerator. Post fixation of the samples was performed $1 \% \mathrm{OsO}_{4}$ (in phosphate buffer, $\mathrm{pH} 7.4$ ), $1 \mathrm{~h}$ at $4^{\circ} \mathrm{C}$ in refrigerator. The samples in the wells of 
the plate were washed twice with PBS, and dehydrated in ethanol ascending concentrations: $10 \%, 20 \%, 30 \%, 40 \%, 50 \%, 60 \%, 70 \%, 80 \%, 90 \%$ and $100 \%$ (twice), $5 \mathrm{~min}$ at each concentration at room temperature. After dehydration with ethanol, the scaffolds with adherent cells were removed from the wells and washed twice with $100 \%$ acetone. The scaffolds with adherent cells were sticked to a copper plate and dried in vacuum-assisted desiccators overnight and then stored at room temperature till SEM analysis was carried out. The surface of the scaffolds was sputter-coated in a vacuum with an electrically conductive $5 \mathrm{~nm}$ thick layer of gold alloy Precession Etching Coating system (Gatan Model 682, Inc. USA). The prepared assay samples were analyzed by scanning microscope Quanta FEI 200 (USA) (Parameswaran, 2011).

For each donor in each experimental variant were analyzed 4-5 scaffolds with adherent cells. On each scaffold in random fields were counted 80-100 cells and distributed them according to morphological classes.

The total number of analyzed cells was taken as $100 \%$. The number of cells in different morphological classes expressed as a percentage of the total number of cells.

\section{Statistical analyses}

Statistical analysis of the results was performed by conventional methods, using the standard software package of Microsoft Excel. Arithmetic means and standard deviations were found. The statistical significance of results was determined using Student's test. Statistically significant differences were accepted at $\mathrm{P} \leq 0.05$ level.

\section{RESULTS AND DISCUSSION.}

Effects of P3HB- and P3HB/4HB10-biopolymeric particles and fibers on the activity of MTT-reduction in monocytes 
Optical density values for cell viability show marked variability among different samples, depending on the chemical composition, structure and size of particles, as shown in Table1.

Thus, cultivation of cells in direct contact with P3HB/4HB10 particles larger than $200 \mathrm{~nm}$ (P3HB/4HB10, > $200 \mathrm{~nm}$ ) did not affect their metabolic activity as compared to control ( $\mathrm{P}=\mathrm{NS})$. On the other hand, exposure of cells with PH3B particles of the same size, > $200 \mathrm{~nm}$, caused a significant reduction in monocyte viability $(p \leq 0.05)$. The ability of monocytes to reduce MTT was decreased, also, upon treatment with the copolymeric particles P3HB/4HB10, < $200 \mathrm{~nm}$. Interestingly, size of $\mathrm{P} 3 \mathrm{HB}$ particles did not alter their effects on monocyte viability being similar for both $\mathrm{P} 3 \mathrm{HB}>200 \mathrm{~nm}$ and $\mathrm{P} 3 \mathrm{HB}<200 \mathrm{~nm}$ particles $(p \leq 0.05)$, respectively. This phenomenon may be consequence of well-known marked hydrophobicity of P3HB.

Short-term cultivation of monocytes on $\mathrm{P} 3 \mathrm{BH}$ and $\mathrm{P} 3 \mathrm{HB} / 4 \mathrm{HB} 10$ fibrous scaffolds was associated with discrete effects on the ability of monocytes to reduce MTT. Indeed, only exposure to the P3HB substrates with oriented fibers caused noticeable decrease of monocytes to reduce MTT, $(p \leq 0.05)$. Thus, it should be noted, that the orientation of fibers affects the results of the MTT.

Cellular molecular mechanisms participating in MTT reduction are not fully established, where the participation of $\mathrm{NAD}(\mathrm{P}) \mathrm{H}$-dependent oxidoreductases or other reducing molecules in electron transfer to the MTT are suggested (Marshall et al., 1995 Berridge et al., 2005). Indeed, it is indicated that the cellular reduction of MTT may depend on the activity of mitochondrial enzymes (Berridge et al, 1993,. 1996). It should be noted, that MTT reduction processes depend to a large extent, on the activity of metabolic cycles associated with $\mathrm{NAD}(\mathrm{P}) \mathrm{H}$ streams. Thus, cells with low metabolic activity, as thymocytes and splenocytes, reduce lower amounts of MTT. It must be borne in mind that under certain cultivation conditions changes in metabolic activity are responsible for lower cellular reduction of MTT but not the decrease in cell viability (Berridge et al., 1993; 1996; Safi et al., 2016)

These results indicate a high "sensitivity" of monocyte culture as a test system for the integrated evaluation of the biological activity of BNMs with different composition, dimensional and morphological features

Effect of $F$ and ND on the activity of MTT reduction and morphology of monocytes

In continuation we evaluated the effects of $\mathrm{F}$ and ND particle treatment on monocyte metabolic activity. Also, for the comparative assessment these particles were functionalized with a 
protein "corona". In the samples with F-particles no affect on monocyte activity was evident as compared to the control (cultivation on $\mathrm{P} 3 \mathrm{HB} / 4 \mathrm{HB} 10$ film scaffolds) at all studied concentrations (Table 2). Pre-coating of $\mathrm{F}$ with a protein corona, $\mathrm{F}+\mathrm{PC}$, had no further effect. Interestingly, when monocytes were treated with ND in concentrations up to $50 \mu \mathrm{g} / \mathrm{mL}$, the cellular reduction of MTT increased, as compared with control (Table. 2). This may be due to enhanced production of reactive oxygen species in mitochondria compartment of monocytes. However, after the preforming of PC on NDs in the wells with concentration $50 \mu \mathrm{g} / \mathrm{mL}$, the MTT cellular reduction was even lower the controls. These data suggests that the protein corona may influence both the internalization of ND and ND-dependent intracellular effects, in particular the pool of reducing agents, involved in the reactions with MTT.

Processes of internalization of $\mathrm{F}$ and NDs and subsequent reactions intracellular signaling pathways can be accompanied by significant restructuring in the organization of the plasma membrane and cell morphology as a whole. Therefore, the next stage of our research was the performing of morphological analysis of cells in various culture conditions.

\section{The effects of NPs on monocyte morphology}

Electron microscopy demonstrated that NPs have a type and structure - dependent effect on monocyte phenotype (Figure 1, Table 3). Under the control conditions, e.g. culture on P3HB/4HB10 substrates, four monocyte phenotypes were evident; the dominant being spherical cells with "microvilli" on the surface (54\% of the total cell population) (class 1 in Table 3, Figure 1a). In addition, adherent cells with ruffles on the surface, (21\%) (class 2 in Table 3, Figure 1b), adherent "flat" cells with complicated membrane relief along the edge, (11\%) (class 3 in Table 3, Figure 1c) and macrophage like cells, 14\% (class 4 in Table 3, Figure 1d) were observed.

The morphological heterogeneity of adherent monocytes in vitro could be attributed to the existence of various morpho-functional subpopulations of circulating monocytes in the bloodstream (Stansfield, et al., 2015; Mikołajczyk, et al., 2016). After the isolation from blood, subpopulations of monocytes implement specific differentiation programs in culture in vitro, particularly as regarding reorganization of the cytoplasmic membrane and the supporting cytoskeleton structure (Di Cosmo-Ponticello et al., 2014; Brown et al, 2014). As a result, the heterogeneity of the cell population is maintained under in vitro conditions (Safi et al. , 2016) 
Exposure to different NPs results in significant changes as regarding the ratio among respective phenotypes of monocytes (Table 3). Moreover, exposure in the case of $\mathrm{F}$ particles at a concentration $25 \mu \mathrm{g} / \mathrm{mL}$ led to the appearance of new morphological class of cells - adherent "flat" cells with a smooth edge (class 5 in Table 3, Figure 1e, f). Cells of this type were often observed in contact with platelets. However, when F particles at $(25 \mu \mathrm{g} / \mathrm{mL})$, were coated with a PC the phenotype of adherent "flat" cells with a smooth edge was not detected, whereas the dominant phenotype was that of spherical cells with "microvilli" on the surface (class 1 in Table 3, Figure 1g). Interestingly, exposure to $\mathrm{F}(50 \mu \mathrm{g} / \mathrm{mL})$ resulted in the appearance of a new morphological class - macrophage like cells, whose surface was "covered" by platelets (class 6 in Table 3, Figure $1 \mathrm{~h})$.

Exposure to ND induced different quantitative relationships between phenotypes, discrepant from both - the control and treatment with F (Table 3). Moreover, the effects of ND with PC were significantly different from the effects of ND without it ("naked" ND). Thus, the number of "flat" cells with complicated membrane edge (class 3 in Table, Figure 1i) was 2 times higher for ND with the protein "corona" as compared for "naked" ND (concentration $25 \mu \mathrm{g} / \mathrm{mL}$ ).

$1 \mathrm{j}$

Based on these results we can assume, that the interaction of $\mathrm{F}$ and ND with different subpopulations of peripheral blood monocytes leads to significant changes in the processes of morphological and functional differentiation of these cell subpopulations in vitro. The exposure of monocytes to NPs, currently in use as a biocompatible implantable materials for medical purposes, exhibited discrete effects on their morphology depending on their chemical structure and utilized processing techniques (Sabeel et al., 2006; Simon et al., 1999; Sinskey et al., 2012). Thus, under the influence of $\mathrm{F}$ the subpopulation of monocytes differentiated, exhibiting increased adhesiveness for platelets. This phenomenon can be a consequence of the activation of cytokines synthesis, which attract platelets, as well as of alterations in the expression of specific adhesion molecules which contribute to platelet-monocyte adhesion platelets. It should also be noted, that in the contact groups monocyte-platelets, last maintained a smooth spherical shape.

In the present study the interaction of NPs was evaluated at two levels: (i) internalization of NPs and (ii) interaction of monocytes with biopolymeric scaffolds. During these interactions adhesive contacts were formed between cells and NPs where cells exert mechanical force. This idea comes from studies of adhesive properties of cells where specific adhesion molecules, e.g. integrins 
act as mechanical conduits between the extracellular matrix and the cytoskeleton located to cell interior (Klotzsch et al., 2015). The generated mechanical forces have the ability to rearrange proteins laterally, which may result in protein clustering as well as regulate their specific activities (Gomez and Billadeau, 2008).

In other model systems the incorporation of natural products, including heparin and its derivatives leads to morphological changes in the actin cytoskeleton and altered melanoma adhesion and migration properties (Low molecular weight heparin inhibits melanoma cell adhesion and migration (Chalkiadaki et al., 2011a,b)

In our experimental model the specific intereactions with discrete NPs are translated in morphological changes of monocytes. )

Я не поняла, зачем тут клетки меланомы появились..... Thus, effects of F and ND on the processes of morphological and functional differentiation of monocytes subpopulations can be realized: a) through the system of receptor-dependent internalization; b) taking into account the dimensional features of $\mathrm{F}$ and ND, through non-receptor interactions of NPs with the plasma membrane and the activation of mechano-chemical signaling. Further studies are necessary to determine the contribution of the proposed approaches.

So, marked changes of monocyte phenotypes during exposure to NPs under short-term cultivation allow the use of morphological criteria for preliminary assessment of the effects of various structural types of biopolymeric nanomaterials on the processes of differentiation of monocytes subpopulations.

\section{CONCLUSION}

1. The ability of monocytes to reduce MTT, under short term culturing, upon exposure with bionanomaterials, having particular or fibrous morphology, is dependent on BNMs-chemical composition, size and "morphological" / structural characteristics.

2. $\mathrm{F}$ in the studied concentrations did not affect the human blood monocyte ability to reduce formazan in vitro, regardless PC, whereas NDs in concentration of $50 \mu \mathrm{g} / \mathrm{mL}$ in suspension significantly increased the MTT value, and after PC preforming -decreased it some few.

3. Monocyte phenotype and ratio among different phenotypic groups were significantly modified with the presence of ND and F, as compared to control - P3HB/4HB10 film substrates. 
The effects were dependent on the concentration of particles in suspensions; preforming of a protein corona on ND and F significantly modified their effects on monocyte morphology also.

4. Short-term culture of monocytes is a potentially suitable model express-system for evaluating of biological effects of nanomaterials.

\section{LITERATURE}

1. Berridge MV, Tan AS. (1993) Characterization of the cellular reduction of 3-(4,5dimethylthiazol-2-yl)-2,5-diphenyltetrazolium bromide (MTT): subcellular localization, substrate dependence, and involvement of mitochondrial electron transport in MTT reduction. Archives of biochemistry and biophysics 303 (2): 474-482

2. Berridge M. Tan A. McCoy K. Wang R. (1996) The biochemical and cellular basis of cell proliferation assays that use tetrazolium salts. Biochemica 4: 14-19

3. Bharde A.A., Palankar R., Fritsch C., Klaver A., Kanger J.S., Jovin T.M., Arndt-Jovin D.J. (2013) Magnetic nanoparticles as mediators of ligand-free activation of EGFR signaling. Public Library of Science One 8(7):e68879

4. Brown S., Hutchinson C.V., Aspinall-O'Dea M., Whetton A.D., Johnson S.M., Rees-Unwin K., Burthem J. (2014) Monocyte-derived dendritic cells from chronic myeloid leukaemia have abnormal maturation and cytoskeletal function that is associated with defective localisation and signalling by normal ABL1 protein. European journal of haematology 93(2):96-102

5. Chalkiadaki G., Nikitovic D., Katonis P., Berdiaki A., Tsatsakis A., Kotsikogianni I., Karamanos N.K., Tzanakakis G.N. (2011a) PKCa/JNK signaling pathway inducing actin cytoskeleton changes. Cancer Letter 312(2):235-244 
6. Chalkiadaki G., Nikitovic D., Berdiaki A., Katonis P., Karamanos N.K., Tzanakakis G.N. (2011b) Heparin plays a key regulatory role via a p53/FAK-dependent signaling in melanoma cell adhesion and migration. IUBMB Life 63(2):109-119

7. Curtis A.S., Tsimbouri P.M. (2014) Epigenesis: roles of nanotopography, nanoforces and nanovibration. Expert Review of Medical Devices 11(4):417-423

8. Di Cosmo-Ponticello C.J., Hoover D., Coffman F.D., Cohen S., Cohen M.C. (2014) MIF inhibits monocytic movement through a non-canonical receptor and disruption of temporal Rho GTPase activities in U-937 cells. Cytokine 69(1):47-55

9. Di Silvio D., Rigby N., Bajka B., Mackie A., Baldelli Bombelli F. (2015) Effect of protein corona magnetite nanoparticles derived from bread in vitro digestion on Caco-2 cells morphology and uptake. International Journal of Biochemistry and Cell Biology S1357-2725

10. Echarri A., Del Pozo M.A. (2015) Caveolae - mechanosensitive membrane invaginations linked to actin filaments Journal of Cell Science 128(15):2747-2758.

11. Farokhzad O.C., Langer R. (2006) Nanomedicine: Developing smarter therapeutic and diagnostic modalities. Advanced drug delivery reviews 58(14):1456-9.

12. Fleischer C.C., Payne C.K. (2014) Nanoparticle-cell interactions: molecular structure of the protein corona and cellular outcomes. Accounts of Chemical Research 47(8):2651-2659

13. Galic M., Begemann I., Viplav A., Matis M. (2014) Force-control at cellular membranes. Bioarchitecture 4(4-5):164-168

13. Gomez T.S. , Billadeau D.D. (2008) T cell activation and the cytoskeleton: you can't have one without the other. Advances in immunology 97:1-64

14. Hata K., Higashisaka K., Nagano K., Mukai Y., Kamada H., Tsunoda S., Yoshioka Y., Tsutsumi Y. (2014) Evaluation of silica nanoparticle binding to major human blood proteins. Nanoscale Research Letters 9(1):2493

15. Henstock J., Haj A. (2015) Controlled mechanotransduction in therapeutic MSCs: can remotely controlled magnetic nanoparticles regenerate bones. Regenerative Medicine 10(4):377-380

16. Henstock J.R., Rotherham M., Rashidi H., Shakesheff K.M., El Haj A.J. (2014) Remotely activated mechanotransduction via magnetic nanoparticles promotes mineralization synergistically with bone morphogenetic protein 2: applications for injectable cell therapy. Stem Cells Translational Medicine 3(11):1363-1374

17. Khalili F. J., Jafari S., Eghbal M.A. (2015) A Review of molecular mechanisms involved in toxicity of nanoparticles. Advanced pharmaceutical bulletin 5(4):447-454 
18. Kilinc D., Dennis C.L., Lee G.U. (2016) Bio-nano-magnetic materials for localized mechanochemical stimulation of cell growth and death. Advanced Materials doi: 10.1002/adma.201504845

19. Klotzsch E., Stiegler J., Ben-Ishay E., Gaus K. (2015) Do mechanical forces contribute to nanoscale membrane organisation in T cells? Biochimica et biophysica acta. 1853(4):822-829

20. Lee J.H., Kim J.W., Levy M., Kao A., Noh S.H., Bozovic $\quad$ D., Cheon J. (2014) Magnetic nanoparticles for ultrafast mechanical control of inner ear hair cells. American Chemical Society Nano 8(7):6590-6598.

21. Marshall N.J., Goodwin C.J., Holt S.J. (1995) A critical assessment of the use of microculture tetrazolium assays to measure cell growth and function. Growth Regulation 5 (2): 69-84.

22. Matczuk M., Anecka K., Scaletti F., Messori L., Keppler B.K., Timerbaev A.R., Jarosz M. (2015) Speciation of metal-based nanomaterials in human serum characterized by capillary electrophoresis coupled to ICP-MS: a case study of gold nanoparticles. Metallomics 7(9):13641370

23. Mikołajczyk T.P., Osmenda G., Batko B., Wilk G., Krezelok M., Skiba D., Sliwa T., Pryjma J.R., Guzik T.J. (2016) Heterogeneity of peripheral blood monocytes, endothelial dysfunction and subclinical atherosclerosis in patients with systemic lupus erythematosus. Lupus 25(1):18-27

24. Mortimer G.M., Butcher N.J., Musumeci A.W., Deng Z.J., Martin D.J., Minchin R.F. (2014) Cryptic epitopes of albumin determine mononuclear phagocyte system clearance of nanomaterials. American Chemical Society Nano 8(4):3357-3366

25. Parameswaran S., Verma R.S. (2011) Scanning electron microscopy preparation protocol for differentiated stem cells. Analytical biochemistry 416(2):186-190.

26. Polyak B., Cordovez B.(2016) How can we predict behavior of nanoparticles in vivo. Nanomedicine (London) doi:10.2217/nnm.15.192

27. Recalde H.R. (1984) A simple method of obtaining monocytes in suspension. Journal of Immunological Methods 69(1):71-77

28. Safi W., Kuehnl A., Nüssler A., Eckstein H.H., Pelisek J. (2016) Differentiation of human CD14+ monocytes: an experimental investigation of the optimal culture medium and evidence of a lack of differentiation along the endothelial line. Experimental and molecular medicine 48:e227. doi: 10.1038/emm.2016.11.

29. Shannahan J.H., Podila R., Brown J.M. (2015) A hyperspectral and toxicological analysis of protein corona impact on silver nanoparticle properties, intracellular modifications, and macrophage activation. International Journal of Nanomedicine 10:6509-6521 
30. Shishatskaya E.I., Nikolaeva E.D., Goreva A.V., Brigham C.J., Volova T.G., Sinskey A.J. (2012) Investigation in vivo of films made of resorbable polyhydroxyalkanoates with different composition: tissue reaction and kinetics of biodestruction. Cell transplantation and tissue engineering 7: 73-80 (In Russian)

31. Stansfield B.K., Ingram D.A. (2015) Clinical significance of monocyte heterogeneity. Clinical and Translational Medicine 4:5. doi: 10.1186/s40169-014-0040-3

32. Valappil S.P., Misra S.K., Boccaccini A.R., Roy I. (2006) Biomedical applications of polyhydroxyalkanoates, an overview of animal testing and in vivo responses. Expert Rev. Med. Devices 3(6): 854-868

33. Williams S.F., Martin D. P., Horowitz D. M., Peoples O.P. (1999) PHA applications: addressing the price performance, issue I. Tissue engineering International Journal of Biological Macromolecules 25:111-121

34. Zanganeh S., Spitler R., Erfanzadeh M., Mahmoudi M. (2016). Protein corona: opportunities and challenges. International Journal of Biochemistry and Cell Biology S1357-2725 

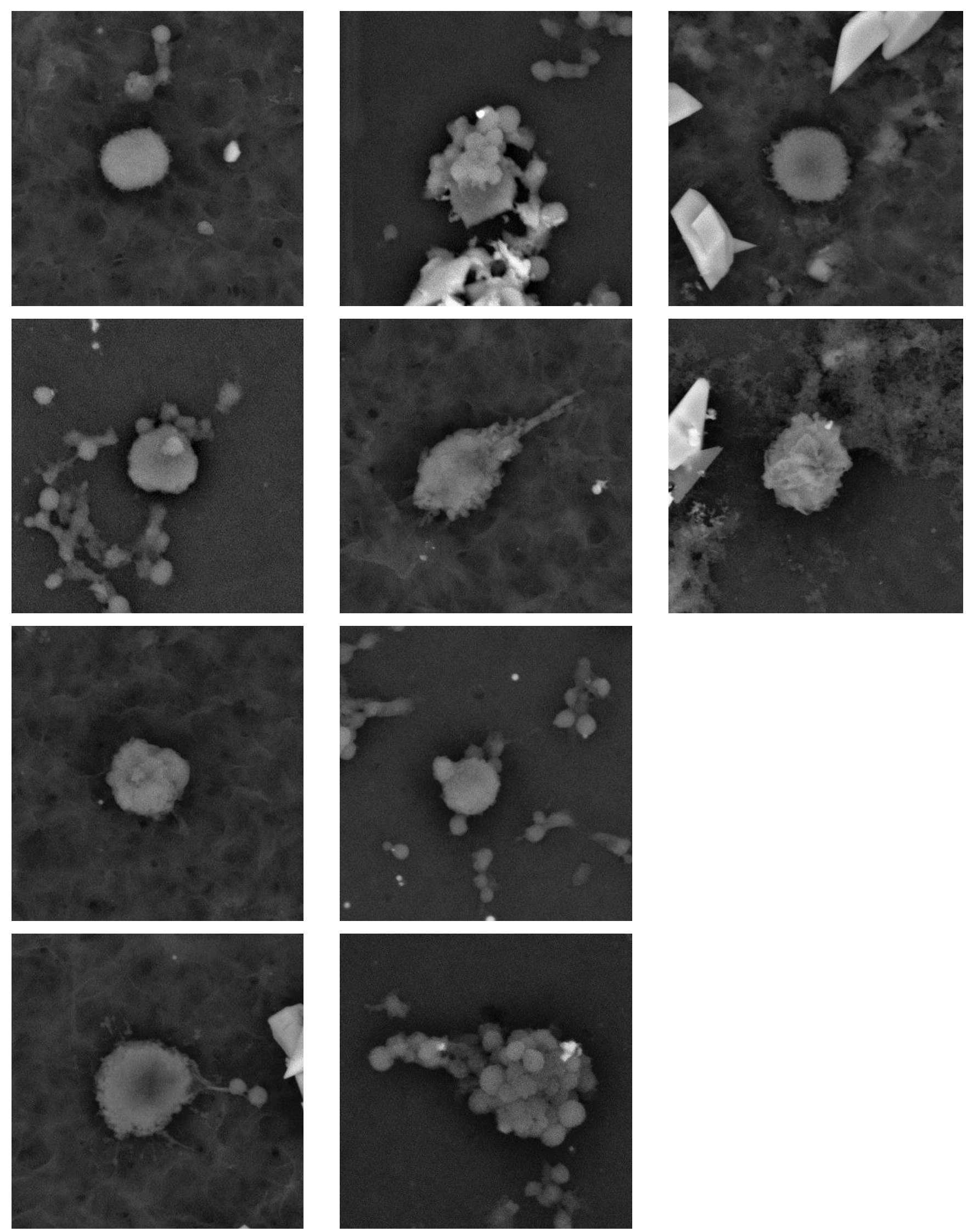
Table 1. Activity of reducing of MTT (MTT-assay) by monocytes at different cultivation conditions.

Monocytes were cultured in 96-well cultural plates. In the control variant, Tissue Culture Plastic, TCP, $10^{5}$ cells in $160 \mu \mathrm{L}$ DMEM, $10 \%$ fetal serum per well were added. In experimental variants with biopolymeric particles $10^{5}$ cells in $80 \mu \mathrm{L}$ DMEM, $10 \%$ fetal serum and $80 \mu \mathrm{L}$ of suspensions of particles in DMEM, $10 \%$ fetal serum per well were added; the final particle concentration was of $0,5 \mathrm{mg} / \mathrm{mL}$. In experimental variants with biopolymeric fibers substrates sterile samples of substrates were placed on the bottom of the wells and applied $10^{5}$ cells in $160 \mu \mathrm{L}$ DMEM, 10\% fetal serum per well. All samples were incubated for $36 \mathrm{~h}$.

MTT-assay results are presented as a percentage of absorbance $\left(\mathrm{E}_{570}\right)$ in control variant.

\begin{tabular}{cccc}
\hline \multicolumn{2}{c}{ Biopolymeric particles } & \multicolumn{2}{c}{ Biopolymeric fibers } \\
\hline Variants of particles & $\begin{array}{c}\text { MTT- assay, } \\
\% \text { of control } \\
\text { variant }\end{array}$ & Variants of fibers & $\begin{array}{c}\text { MTT- assay, } \\
\% \text { of control } \\
\text { variant }\end{array}$ \\
\hline P3HB, $<200 \mathrm{~nm}$ & $64 \pm 7^{\wedge}$ & P3HB, oriented fibers & $80 \pm 9$ \\
\hline P3HB, $>200 \mathrm{~nm}$ & $50 \pm 7^{\wedge}$ & P3HB, nonoriented fibers & $59 \pm 7^{\wedge}$ \\
\hline P3HB/4HB10< $200 \mathrm{~nm}$ & $64 \pm 8^{\wedge}$ & P3HB50 + PL25/PG25 Z & $75 \pm 8$ \\
\hline P3HB /4HB10 > 200 nm & $95 \pm 11^{\#}$ & P3HB50 + PL50 & $77 \pm 9$ \\
\hline
\end{tabular}

$\wedge$ - significant differences from the control variant $(\mathrm{p}<0,05)$.

\# - significant differences of the variant P3HB/4HB10 > $200 \mathrm{~nm}$ from the variant $\mathrm{P} 3 \mathrm{HB} / 4 \mathrm{HB} 10<200 \mathrm{~nm}(\mathrm{p}<0,05)$. 
Table 2. Activity of reducing of MTT (MTT-assay) by monocytes at different cultivation conditions.

For all the control and experimental variants at the bottom of the wells of a 96-well cultural plate were placed sterile P3HB/4HB10-biopolymer scaffolds. In the control variant $10^{5}$ cells in 160 $\mu \mathrm{L}$ DMEM, $10 \%$ fetal serum per well were added.

In experimental variants with nanodiamonds and fullerenes $10^{5}$ cells in $80 \mu \mathrm{L}$ DMEM, $10 \%$ fetal serum and $80 \mu \mathrm{L}$ of solutions of nanoparticles in DMEM, $10 \%$ fetal serum per well were added. The final nanoparticle concentrations were $2,5 \mu \mathrm{g} / \mathrm{mL}, 25 \mu \mathrm{g} / \mathrm{mL}, 50 \mu \mathrm{g} / \mathrm{mL}$. All samples were incubated for $36 \mathrm{~h}$.

MTT-assay results are presented as a percentage of absorbance $\left(\mathrm{E}_{570}\right)$ in control variant.

P3HB/4HB10 (Control) - cultivation on a P3HB/4HB10-biopolymer scaffolds; $\mathrm{P} 3 \mathrm{HB} / 4 \mathrm{HB} 10+\mathrm{F}-$ cultivation on a P3HB/4HB10-biopolymer scaffolds with fullerenes; P3HB/4HB10 + ND - cultivation on a P3HB/4HB10-biopolymer scaffolds with nanodiamonds; $\mathrm{P} 3 \mathrm{HB} / 4 \mathrm{HB} 10+(\mathrm{F}+\mathrm{PC})-$ the cultivation on a P3HB/4HB10-biopolymer scaffolds with fullerenes with protein corona; $\mathrm{P} 3 \mathrm{HB} / 4 \mathrm{HB} 10+(\mathrm{ND}+\mathrm{PC})-$ the cultivation on a P3HB/4HB10 biopolymer scaffolds with nanodiamonds with protein corona.

\begin{tabular}{cccc}
\hline \multirow{2}{*}{ Cultivation options } & \multicolumn{2}{c}{ The concentration of nanoparticles in the culture medium } \\
\hline & $2,5 \mu \mathrm{g} / \mathrm{mL}$ & $25 \mu \mathrm{g} / \mathrm{mL}$ & $50 \mu \mathrm{g} / \mathrm{mL}$ \\
\hline $\mathrm{P} 3 \mathrm{HB} / 4 \mathrm{HB} 10+\mathrm{F}$ & $94 \pm 10$ & $113 \pm 16$ & $100 \pm 14$ \\
\hline $\mathrm{P} 3 \mathrm{HB} / 4 \mathrm{HB} 10+(\mathrm{F}+\mathrm{PC})$ & $107 \pm 10$ & $116 \pm 18$ & $107 \pm 12$ \\
\hline $\mathrm{P} 3 \mathrm{HB} / 4 \mathrm{HB} 10+\mathrm{ND}$ & $104 \pm 11$ & $104 \pm 13$ & $88 \pm 13^{* *}$ \\
\hline $\mathrm{P} 3 \mathrm{HB} / 4 \mathrm{HB} 10+(\mathrm{ND}+\mathrm{PC})$ & $107 \pm 10$ & $100 \pm 8$ & \\
\hline
\end{tabular}

** - significant differences from the control variant (P3HB/4HB10 -biopolymer scaffolds) and the experimental variant $\mathrm{P} 3 \mathrm{HB} / 4 \mathrm{HB} 10+(\mathrm{ND}+\mathrm{PC}), 50 \mu \mathrm{g} / \mathrm{mL},(\mathrm{p}<0,05)$. 
Table III

Table 3. The effects of nanoparticles on monocyte morphology. The number of cells in each morphological class is expressed in percentage of total analyzed cells $(n=300)$ in each cultivation variants.

Culture conditions are described in Table 2.

P3HB/4HB10 (Control) - cultivation on a P3HB/4HB10-biopolymer scaffolds; $\mathrm{P} 3 \mathrm{HB} / 4 \mathrm{HB} 10+\mathrm{F}-$ cultivation on a P3HB/4HB10-biopolymer scaffolds in the presence of fullerenes; P3HB/4HB10 + ND - cultivation on a P3HB/4HB10-biopolymer scaffolds in the presence of nanodiamonds; $\mathrm{P} 3 \mathrm{HB} / 4 \mathrm{HB} 10+(\mathrm{F}+\mathrm{PC})-$ the cultivation on a $\mathrm{P} 3 \mathrm{HB} / 4 \mathrm{HB} 10$ biopolymer scaffolds in the presence of fullerenes with protein corona; $\mathrm{P} 3 \mathrm{HB} / 4 \mathrm{HB} 10+(\mathrm{ND}+$ PC) - the cultivation on a P3HB/4HB10-biopolymer scaffolds in the presence of nanodiamonds with protein corona.

Morphological classes of monocytes

\begin{tabular}{|c|c|c|c|c|c|c|}
\hline $\begin{array}{c}\text { Variants of culture } \\
\text { conditions }\end{array}$ & 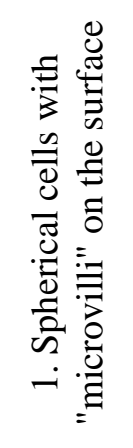 & 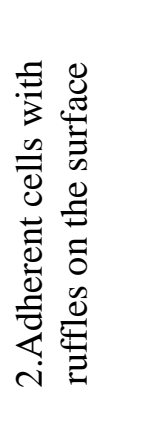 & 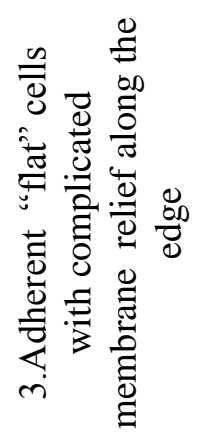 & 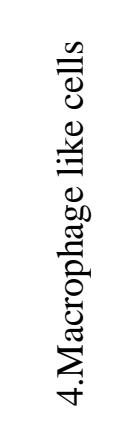 & 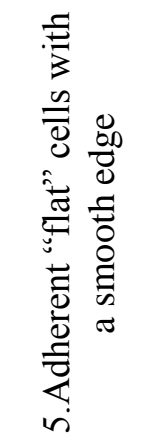 & 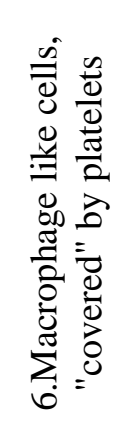 \\
\hline $\begin{array}{l}\text { P3HB/4HB10 } \\
\text { (Control) }\end{array}$ & $54 \pm 6,5$ & $21 \pm 3,2$ & $11 \pm 1,3$ & $14 \pm 1,8$ & 0 & 0 \\
\hline $\begin{array}{l}\text { P3HB/4HB10 } \\
+\mathrm{F}, 25 \mu \mathrm{g} / \mathrm{mL}\end{array}$ & $8 \pm 1,1$ & $4 \pm 0,6$ & $4 \pm 0,7$ & $4 \pm 0,5$ & $80 \pm 10,3$ & 0 \\
\hline $\begin{array}{l}\text { P3HB/4HB10 } \\
+(\mathrm{F}+\mathrm{PC}) \\
25 \mu \mathrm{g} / \mathrm{mL}\end{array}$ & $50 \pm 6,7$ & $33 \pm 4,2$ & $17 \pm 2,1$ & 0 & 0 & 0 \\
\hline $\begin{array}{l}\text { P3HB/4HB10 } \\
+\mathrm{F}, 50 \mu \mathrm{g} / \mathrm{mL}\end{array}$ & $24 \pm 2,5$ & $1 \pm 0,3$ & $10 \pm 1,4$ & $13 \pm 1,7$ & 0 & $50 \pm 4,5$ \\
\hline $\begin{array}{l}\text { P3HB/4HB10 } \\
+\mathrm{ND} \\
25 \mu \mathrm{g} / \mathrm{mL}\end{array}$ & $55 \pm 6,2$ & $10 \pm 1,4$ & $20 \pm 2,4$ & $5 \pm 0,8$ & $10 \pm 1,3$ & 0 \\
\hline $\begin{array}{l}\text { P3HB/4HB10 } \\
+(\mathrm{ND}+\mathrm{PC})\end{array}$ & $40 \pm 4,8$ & $13 \pm 1,6$ & $47 \pm 5,2$ & 0 & 0 & 0 \\
\hline
\end{tabular}




\begin{tabular}{|c|c|c|c|c|c|c|}
\hline \multicolumn{7}{|l|}{$25 \mu \mathrm{g} / \mathrm{mL}$} \\
\hline $\begin{array}{l}\text { P3HB/4HB10 } \\
+\mathrm{ND}, 50 \mu \mathrm{g} / \mathrm{mL}\end{array}$ & $50 \pm 5,6$ & $43 \pm 5,1$ & $2 \pm 0,3$ & $5 \pm 0,7$ & 0 & 0 \\
\hline $\mathrm{P} 3 \mathrm{HB} / 4 \mathrm{HB} 10$ & & & & & & \\
\hline $\begin{array}{l}+(\mathrm{ND}+\mathrm{PC}) \\
50 \mu \mathrm{g} / \mathrm{mL}\end{array}$ & $70 \pm 8,1$ & $11 \pm 1,5$ & $15 \pm 1,8$ & $4 \pm 0,6$ & 0 & 0 \\
\hline
\end{tabular}

